\title{
Afro-colombianidade e outras narrativas \\ a Educação Própria como agenda emergente*
}

\author{
CLAUDIA MIRANDA \\ Universidade Federal do Estado do Rio \\ de Janeiro, Rio de Janeiro, RJ, Brasil
}

RESUMO

Neste artigo apresentamos algumas análises sobre a força do movimento social afro-colombiano e sua agenda política, que tem como centralidade defender a chamada educação própria. Discutimos também a promoção das referências históricas e culturais do movimento, no intuito de recolocar as relações historicamente estabelecidas como hierárquicas. As críticas aos modelos de políticas de "inclusão", apresentadas em fóruns diversos organizados na Colômbia e no seu entorno, e a participação dos ativistas, no intuito de garantir ações estratégicas, orientaram nossas análises, que são aqui apresentadas em diálogo com autores fundamentais ao debate, como é o caso de Catherine Walsh (2003, 2007, 2008), Fanny Milena Quiñones (2010), Santiago Arboleda (2002) e Santiago Castro-Gómez (2009, 2010). Destacamos ser imperativo admitirmos a relevância dos estudos atuais sobre novos lugares discursivos.

\section{PALAVRAS-CHAVE}

movimento social afro-colombiano; Educação Própria; agenda política; contranarrativas.

* Este artigo, em sua versão inicial, foi apresentado na 35a Reunião Anual da Associação Nacional de Pós-Graduação e Pesquisa em Educação (ANPEd), realizada em Porto de Galinhas/Ipojuca (PE), de 21 a 24 de outubro de 2012, sendo amplamente discutido no Grupo de Trabalho de Movimentos Sociais, Sujeitos e Processos Educativos (GT03). 


\title{
AFRO-COLOMBIAN AND OTHER NARRATIVES: SELF-EDUCATION AS AN EMERGENT AGENDA
}

\begin{abstract}
In this paper we present some analyses of the strength of the afro-colombian social movement and its political agenda which focus is to defend so called self-education. We also discuss the promotion of their historical and cultural references aiming to redefine historically established relationships as hierarchical. The criticism of the policy models of "inclusion" presented in several forums organized in Colombia and the surrounding area, and the participation of activists to ensure strategic actions, guided our analyzes. These are presented in discussions with key authors like Catherine Walsh (2003,2007, 2008), Fanny Milena Quiñones (2010), Santiago Arboleda (2002), and Santiago Castro-Gómez (2009, 2010). We emphasize that it is imperative to admit the relevance of the current studies on new perspectives.
\end{abstract}

\section{KEYWORDS}

afro-colombian social movement; Self-Education; political agenda; counter-narratives.

\section{AFROCOLOMBIANIDAD Y OTRAS NARRATIVAS: LA EDUCACIÓN PROPIA COMO AGENDA EMERGENTE}

\section{RESUMEN}

En ese artículo presentamos algunos análisis sobre la fuerza del movimiento social afrocolombiano y su agenda política, que tiene como centralidad defender la llamada educación propia. Discutimos, también, la promoción de referenciales históricos y culturales del movimiento, en el sentido de reubicar las relaciones historicamentes establecidas como jerárquicas. Las críticas a los modelos de políticas de "inclusión" presentadas en foros diversos organizados en Colombia y alrededores y la participación de los activistas -en el sentido de garantizar acciones estratégicas- orientaron nuestros análisis. Dichos análisis se presentan en diálogo con autores fundamentales al debate, como es el caso de Catherine Walsh (2003, 2007, 2008), Fanny Milena Quiñones (2010), Santiago Arboleda (2002) y Santiago Castro-Gómez (2009, 2010). Destacamos como imperativo admitir la relevancia de los estudios actuales sobre nuevos lugares discursivos.

\section{PALABRAS CLAVE}

movimiento social afrocolombiano; Educación Propia; agenda política; contranarrativas. 
Como vertente de grande expressão teórica, a crítica pós-colonial melhor se traduz por examinar produções nascidas do ponto de vista de quem detém o poder de falar sobre os outros da colonização e também de examinar a insurgência de segmentos oriundos das nações ocupadas. Com essa proposta, vimos o movimento social afro-colombiano, de um lado, propondo um conjunto de conceitos para um ementário pertinente de educação intercultural e, de outro, o Estado com um discurso mais fluido sobre a realidade multicultural do país. O discurso estabelecido, do segundo, tem sido confrontado pelo discurso insurgente do movimento afro-colombiano. O texto de apresentação da Biblioteca de literatura afrocolombiana (Colômbia, 2010, s.p.), uma coletânea de livros de contos, novelas, relatos orais, obra de teatro, ensaios e poesias, admite que a diversidade foi "uma realidade que por séculos foi considerada o calcanhar de aquiles para o desenvolvimento econômico, cultural e político". E que hoje é o seu "maior ativo como nação".

Com base em uma perspectiva transdisciplinar, este trabalho é sobre perspectivas interculturais de educação e movimentos sociais na América Latina. Tem como escopo fomentar uma recomposição analítica sobre pedagogias alternativas emergentes no âmbito dos coletivos de maior expressão, na contemporaneidade, no que se refere ao desafio imposto pelas configuraçôes multiculturais ${ }^{1}$ de sociedade.

Os aspectos políticos que adornam o diálogo entre os movimentos sociais e o poder público de uma dada sociedade - examinados com base no quadro teórico dos estudos pós-coloniais (Fanon, 2008; Said, 1990, 1995, 2003) - impõem novos desenhos teórico-metodológicos acerca dos estudos sobre elaboração e execução de propostas educativas com ênfase na valorização da diversidade. Quais seriam as interseções que nos aproximam quando examinamos as mudanças socioeducativas dos afrodescendentes no Brasil e na Colômbia? Há outras pedagogias possíveis orientando formas diversificadas de transposição ${ }^{2}$ do conhecimento a ser ensinado? No âmbito da defesa por espaços colaborativos e dialógicos - em países com grande expectativa de reordenamento socioeducativo de segmentos não brancos -, caberia defendermos pedagogias decoloniais, ${ }^{3}$ como sugerem os afro-colombianos

1 Para nossos estudos, as configurações multiculturais são próprias de contextos em que diferentes coletivos, estratos ou segmentos sociais enfrentam os desafios das suas diferenças culturais, cotidianamente. Ou seja, trata-se de uma realidade desafiadora entre grupos com costumes e histórias distintas pelas suas respectivas heranças ancestrais.

2 A "transposição didática" emerge dos estudos de Yves Chevallard (1991). Os estudos curriculares têm apontado a emergência de pesquisas sobre a história das disciplinas escolares, vislumbrando formas mais adequadas de trabalhar o conhecimento que não seja a didatização, o ensino organizado por matérias escolares. Conforme Lopes (1999), foi em face do grande desenvolvimento das pesquisas em ensino de ciências que alguns conceitos foram elaborados com o intuito de explicar processos de transformação do conhecimento científico em conhecimento escolar. Entre esses, o mais conhecido é o conceito de "transposição didática", desenvolvido por Chevallard e Johsua, conforme Alice Ribeiro Casimiro Lopes (idem).

3 Pedagogias decoloniais é um termo que começa a emergir na área da educação, alinhado com os estudos desenvolvidos no âmbito da América Latina. Assim como Vera Candau e Luis Fernandes, adotamos o termo, uma vez que este trabalho está em 
com a chamada Educação Própria? ${ }^{4}$ Pensando com Catherine Walsh $(2007,2008)$ e Vera Maria Candau (2003), aceitamos a perspectiva intercultural como uma aposta no confronto com as visões diferencialistas que favorecem processos radicais de afirmação de identidades culturais específicas. Trata-se de uma oportunidade de rompimento com uma visão essencialista das culturas e de identidades culturais.

Nos termos de Candau (idem), o conceito - de interculturalidade - constitui-se pela afirmação de que nas sociedades complexas os processos de hibridização cultural são intensos e mobilizadores da construção de identidades fluidas submetidas ao fenômeno da permanente mutação (idem). Sobre o mesmo conceito, Walsh (2007) comparte do significado concebido no âmbito da América Latina, sobretudo no Equador, e que está vinculado à geopolítica de lugares e espaços da histórica e atual resistência dos negros e indígenas. Para a autora,

[...] La interculturalidad señala y significa procesos de construcción de un conocimiento otro, de una práctica política otra, de un poder social (y estatal) otro y de una sociedad otra; una forma otra de pensamiento relacionada con y contra la modernidad-colonialidad y un paradigma otro que es pensado a través de la praxis política. (idem, p. 47)

Pela exigência apresentada por realidades socioeducativas profundamente desiguais no contexto latino-americano, ganha enfoque aquilo que definimos como uma agenda político-pedagógica, no trânsito e na mobilidade social de segmentos sociais envolvidos com propostas de cunho emancipatório para os herdeiros dos Palenques. ${ }^{5}$ Essa realidade exige, portanto, maior destaque para a dinâmica organizacional de um estrato pouco investigado nos trabalhos sobre "Movimentos sociais negros na América Latina", conforme indicam os levantamentos que realizamos ao longo dessa última década.

Como opção metodológica e buscando entrecruzar dados de um mapeamento sobre a organização de pressupostos político-pedagógicos - para apoiar futuras investigações -, consideramos os espaços de intercâmbio acadêmico e político como oportunos para reunir possíveis fontes de consulta de material produzido por esses coletivos. A abordagem inclui um estudo de cunho etnográfico que demandou

diálogo com os principais teóricos(as) dos países vizinhos, tais como Catherine Walsh e Anibal Quijano.

4 Chamaram nossa atenção os livros Sube la marea: Educación Propia e autonomía en los territórios negros del Pacifico (García Rincón, 2008) e Educación pertinente: guía conceptual y práctica para su construcción e implementación (Ylele, 2010), autores conhecidos como etnoeducadores atuantes na defesa do ideário da Educação Própria.

$5 \mathrm{Na}$ Colômbia, de acordo com a literatura encontrada, os Palenques são comunidades afrodescendentes organizadas desde o século XVII, constituídos e liderados por grupos Cimarrones - adeptos de uma ideologia do enfrentamento e luta armada pela libertação. Situados em lugares de difícil acesso, o meio de subsistência foi a agricultura. Contaram, desde o seu início, com lideranças religiosas e políticas orientadas a defender diferentes segmentos africanos escravizados, instituindo a consciência coletiva e a solidariedade. 
inclinação substantiva para compreendermos o tema das relações mistas (Goffman, 1988) entre Estado e movimentos sociais na Colômbia. Isso porque estão em disputa discursos e práticas sociais entendidos como antagônicos e concorrentes. Com base nos dos estudos sobre análise crítica do discurso, nos termos de Norman Fairclough (2003, 2008, 2010), buscamos potencializar esses textos-discursos políticos como objeto de análise.

Conforme Fairclough (2010, p. 226), a metodologia dos estudos sobre análise crítica do discurso é:

[...] a análise das relações dialéticas entre discurso (incluindo não apenas a linguagem verbal, mas outras formas de Semiose, como a linguagem corporal e as imagens visuais) e os outros elementos das práticas sociais. No enfoque assumido por mim, a ACD está especialmente voltada para as mudanças radicais na vida social contemporânea, para os modos pelos quais o discurso está inscrito nelas e para as configurações atuais da relação entre a Semiose e os outros elementos sociais nas redes de práticas. Não é possível assumir o papel do discurso nas práticas sociais como dado, devendo ele ser estabelecido a partir da análise. E o discurso pode ser mais ou menos importante em conjuntos específicos de práticas, além de poder mudar no/com o tempo.

Segundo o quadro teórico do autor, o discurso pode ser concebido como parte da atividade social dentro de uma prática. Pode figurar nas representações quando atores sociais produzem representação sobre os demais ou sua própria prática em exercício. Pode, ainda, integrar os modos de ser e a constituição das identidades. Por tudo isso, inserimos essa abordagem metodológica para compor um quadro teórico possível sobre como nascem os conceitos centrais da agenda político-pedagógica dos movimentos sociais em destaque.

As mudanças promovidas por estratégias diversificadas para pressionar o Estado e, consequentemente, a sociedade colombiana, estão em destaque. Ao que tudo indica, a orientação para os investimentos retóricos em questão gira em torno dos temas da: etnoeducação, territorialidade, etnopolítica e etnodesenvolvimento. São esses os eixos norteadores para pensarmos a problemática educacional afro-colombiana na sua história recente, considerando como pano de fundo os aspectos políticos que definem acordos, os diálogos entre os movimentos sociais e o poder público mediante disputas retóricas.

A partir da elaboração de um estado da arte acerca de discursos sobre etnoeducação, encontramos produções de grupos líderes de comunidades palenqueras, de instituições atuantes nos meios urbanos, material então publicado por docentes especialistas no tema, bem como discursos oficiais que circulam nos documentos regulatórios e conferências diversas.

Nos levantamentos de manifestos, já sistematizados pelas organizações do movimento afro-colombiano, constatamos a existência de proposições sobre a proposta de Educação Própria que apresentam denúncias significativas que nos levaram a supor haver, em jogo, estratégias de manutenção de modelos hierárquicos, de currículo, bem como agendas propositivas sobre mobilidades epistêmicas inspiradas 
em uma abordagem intercultural. Uma perspectiva menos eurocentrada de formação humana e uma histórica preservação da situação que exotiza os "segmentos étnicos", ao que tudo indica, estão em confronto. Nos termos de Edward Said (2003), dialogamos com a "perspectiva subalterna negra" e a crítica pós-colonial, localizando a problemática como parte do ranço de situações de subjugação ainda vigentes.

Seguimos argumentos que entendem as narrativas produzidas e que alimentaram a agenda por uma Educação Própria como um discurso decolonial, um discurso de resistência ao olhar e ao poder daqueles localizados no centro dos processos de dominação também epistêmica. Para ampliarmos os argumentos centrais dessa análise - dinâmica organizacional por uma educação intercultural a partir do movimento social afro-colombiano -, fez sentido pensarmos com Santiago Castro-Gómez (2009, 2010), Catherine Walsh (2003, 2007, 2008), Fanny Milena Quiñones (2010) e Santiago Arboleda (2002, 2011), tendo em vista os resultados de seus respectivos estudos - inseridos no eixo que se dedica a examinar narrativas outras e epistemologias emergentes na América Latina. Ao mapearmos tais referências, consideramos os argumentos de Santiago Arboleda $(2002,2011)$ e, em particular, sua investigação sobre como os afro-colombianos construíram algumas esferas de autonomia em contextos urbanos durante o século XX. Salta aos olhos o que aponta o autor sobre as estratégias de negociação quando estas defendem a chamada Educación Propia, uma aposta na preservação da memória ancestral, manifestações culturais, costumes herdados e refletidos no cultivo da terra.

Podemos supor que essas proposições visam recolocar as relações hierárquicas produzidas ao longo da aventura colonial europeia que afetou toda a região. Passou a ser um imperativo admitirmos sua relevância para entendermos nuances dos lugares de enunciação adotados por sujeitos outsiders, quando comparados aos outros oriundos dos grupos vistos como estabelecidos. Sob essa orientação, a crescente importância das produções sobre pedagogias emancipatórias indica outros modos de engajamento teórico, por assim dizer, para desvelarmos lugares epistêmicos alternativos, aceitando os desafios das políticas que visam à diminuição das desigualdades raciais, sobretudo. Nota-se um tipo de estratégia de convívio inevitável que, conforme Erving Goffman (1988), pode ser interpretada como sendo próprio das relações mistas na sociedade.

Nossa aproximação com os estudos curriculares, etnoeducação e movimentos sociais negros na América Latina acontece baseada em pesquisas iniciadas no Brasil, estas servindo como subsídio para examinarmos proposições mais amplas, advindas de distintos movimentos reivindicatórios. Foram esses os traços indispensáveis à composição de um quadro propositivo no intuito de entendermos o lugar de importância da agência político-pedagógica do movimento afro-colombiano.

\section{ANTECEDENTES HISTÓRICOS SOBRE A DINÂMICA SOCIORRACIAL NA COLÔMBIA}

Orientadas pela convocação da Organização das Nações Unidas (ONU), que declarou o ano de 1971 como o "ano da ação" contra o racismo e a discriminação, 
diversas instâncias das comunidades afro-colombianas se mobilizaram em torno do ideário antirracista. Nesse movimento, alcançaram as primeiras fundamentações legais e institucionais na Constituição do país. Seu artigo transitório de n. 55 deu origem à "Ley 70" no ano de 1993, a qual regulamentou o decreto n. 1.122, de 1998 , que estabelecera elementos legais que reivindicavam, então, as ancestralidades africanas, a dignidade afro-colombiana e os direitos étnico-territoriais.

Nessa conjuntura, e conforme as proposições existentes para regular e ordenar a sociedade, parece haver, implícito, um discurso de revisão da Carta Constitucional visando promover o diálogo entre os movimentos reivindicatórios mencionados e o Estado. Ao levantarmos os dados sobre temas de grande recorrência nos fóruns que acompanhamos nos últimos anos sobre interculturalidade e etnoeducação, evidenciamos incompletudes de informações, por exemplo, para a identificação ${ }^{6}$ dos afrodescendentes no censo oficial. Destacamos a centralidade da afirmação recorrente - no âmbito do movimento afro-colombiano - da importância da criação de ferramentas e instrumentos para registrar a presença da diáspora negra no país em números efetivos. Os Raizales, ${ }^{7}$ por exemplo, caracterizam-se, oficialmente, como um grupo étnico distinto dos afro-colombianos, embora predominem os traços da fenotipia africana. Em outros termos, não se justifica a negação de sua pertença como afro-colombianos

A "Lei 70" (1993) é um exemplo dos desdobramentos da questão afro-colombiana e da agenda por justiça, direito à vida e cidadania. Conforme seu artigo 35, "o Estado deve reconhecer e garantir o direito das comunidades negras de criar suas próprias instituições e comunicação sempre que tais instituições satisfaçam as normas estabelecidas pela autoridade competente".

Nos termos da análise crítica do discurso, reconhecemos indícios de um texto que denota uma visão positiva sobre reorganização social com base em um conjunto de elementos-chave sugerindo vinculações com distintas expressões das culturas dos afro-colombianos presentes em todo o país. Assim, essas fontes indicam as confluências da diáspora negra e os processos de produção de saberes, nos quais estão implicadas as africanidades. Ao mesmo tempo, a intencionalidade explicitada amplia as lacunas para a insurgência de contradiscursos com foco nos direitos sociais negados ao longo da história do país.

Os desdobramentos dessa ambiência de maior abertura - conforme indicam alguns fragmentos de textos curriculares e constitucionais - fazem emergirem novos processos representativos e novas disputas retóricas. Em sua agenda, perguntam sobre o lugar de importância de uma contranarrativa sobre a presença da diáspora

6 Em muitas fontes de pesquisa como teses e etnografias, esses coletivos afro-colombianos são representados textualmente como "camponeses", "pescadores", quando na mesma situação de ocupação territorial a população indígena é reconhecida como grupo(s) étnico(s).

7 De fala criolo - uma língua de base inglesa que utiliza expressões gramaticais africanas e outras já consideradas próprias - são, notadamente, afrodescendentes em território nacional. Estão localizados nas regiões dos Vales dos rios Magdalena, Cauca, San Jorge, Sinú, Cesar, Atrato, San Juan, Baudó, Patía e Mira. 
africana na América Latina. Enfatizam um ideário de reordenamento das investigações sobre a gênese das suas manifestações culturais. Por tudo isso, convém destacar aquilo que Castro-Gómez (2009, p. 115) define sobre as tentativas de "gobernar a la población a través de criterios científicos técnicos" de interesse colonial. O registro da história dos africanos nas Américas implica diminuição de privilégios para os segmentos que herdaram as vantagens do colonialismo.

O estudo de Arboleda (2002, p. 400) indica:

Después de un relativo y corto lapso de estabilización y autonomía, que duró aproximadamente cuarenta y cuatro años a partir de 1852, los grupos afrocolombianos de la región del Pacífico sur desplegaron ingentes esfuerzos por el fortalecimiento de sus lazos parentales, instalando, tejiendo poblados, y recreando la vida con la desnudez de sus manifestaciones culturales anidadas en playas marítimas, ríos, quebradas, esteros y demás vericuetos de la geografía costera.

Assim, a lógica integracionista, criticada na literatura, nos fóruns e nos relatos dos coletivos organizados, encontra parte de sua gênese no ideário do projeto de reconquista católica derivado da Constituição de 1886 da Colômbia. Uma década mais tarde, conforme Arboleda (idem), essa reconquista significou um exercício de coerção sobre as práticas cotidianas da cultura popular negra. A partir daí se instaurou um sistema de terror que, ao longo do tempo, implicou o reordenamento territorial em uma lógica integracionista capaz de concentrar a população nas desembocaduras dos rios, indo até o mar e cabeceiras municipais.

A solidariedade política mencionada pelo autor emerge como uma pista para compreendermos a agenda político-pedagógica dos afro-colombianos. As redes familiares foram as responsáveis pelo reavivamento de manifestações culturais que perderam espaço por um longo tempo de deslocamento das comunidades oriundas, sobretudo, do Pacífico e da Costa Caribenha. Como consequência, a aquisição de casas em centros urbanos estimulou a chegada de um maior número de migrantes, além de facilitar o exercício de importantes níveis de autonomia na construção de identidades étnicas e produção de discursos e práticas relevantes na "perspectiva política del nosotros frente al ellos” (idem, p. 406).

$\mathrm{Na}$ historiografia sobre esses modos de organização, há, portanto, estratégias que revelam "la consciencia de la historicidad diferenciada": [...] "el ser negro o paisano es un dispositivo de cohesión que otorga fortalezas frente a las hostilidades del contexto mediante la ampliación y la flexibilización de las redes que, en ese momento, se presentan como un amplio tejido étnico informal" (idem, p. 407). Saltam aos olhos as diferentes etapas que marcam a luta pelo pertencimento social dos afrodescendentes ao longo da história da Colômbia. Sabe-se que, entre os anos de 1930 e 1950, a exigência por um alinhamento político envolvendo os partidos Liberal e Conservador gerou um marco na história recente, a chamada "Violência de 48" - resultando em perseguições, assassinatos e uma guerra não assumida. A questão territorial é, portanto, o pano de fundo desse cenário no qual os afro-colombianos estão implicados. Ao que tudo indica, não podemos deixar de 
considerar o conflito pela terra e os prejuízos advindos dessa problemática. Os estudos mais profícuos sobre desenvolvimento socioeconômico incluem a Colômbia como um dos países mais violentos da região.

Arboleda (idem, p. 403) enfatiza o fato de que entre os anos de 1940 e 1950 se desenvolveu uma intensa mobilidade rural-urbana dessa população do norte do Cauca (Santander e Puerto Tejada), do Vale de Patía (Patía e El Burdo) e da Zona Pacífica especialmente para Cali. Tendo a violência como realidade, esse deslocamento forçado garantiu a debilitação das comunidades rurais, que migraram para os espaços urbanos e ali se instalaram. Em seguida, Cali se converteu em cidade receptora desses migrantes, em virtude do papel central na vida econômica, política e social da região. A mobilidade rural-urbana foi sendo desenhada nesse período e é característica importante na conformação das agendas por políticas públicas diferencialistas. Por isso, passou a ser imperativo considerarmos as nuances dos modos de reestruturação e colocação de demandas por reconhecimento das condições desumanas desses estratos no interior da Colômbia.

Em nossas proposições, o movimento Negritude pode ser visto como inspiração para a solidariedade política que menciona Santiago Arboleda (2002). Em outros termos, conforme aponta o estudo de Miranda (2006), essa referência está presente na Diáspora Africana e pode ser um componente de fortalecimento das estratégias de reinvenção das identidades afrodescendentes naquele contexto.

Chama atenção o que Roberto Burgos Cantor (2010) afirma sobre a tentativa de igualdade jurídica em 1851, em que o chamado grupo escravizado foi equiparado ao grupo dos senhores de escravos, como cidadãos de uma mesma nação. Uma decisão com vistas a garantir o reconhecimento e o compromisso por parte do Estado, com a população afro-colombiana. A decisão visava proteger a diversidade étnica e cultural da nação, mas não extinguiu o preconceito racial levantado pelo sentimento de superioridade dos "brancos" e "mestiços" nem o sentimento de desonra grupal dos afrodescendentes (idem,p. 397). Nesse processo, "el mayor índice de cohesión grupal y de integración que tienen los blancos y mestizos en Colombia contribuye para que estos reserven para sus miembros las posiciones sociales con mayor potencial de poder e influencia y ayuda a excluir de esas posiciones a los afrocolombianos" (idem, ibidem).

Não são suficientes, para os estudos sobre movimentos sociais presentes na Colômbia, as investigações que situam em uma mesma agenda os indígenas e os afro-colombianos. Sobre a situação atual dos grupos organizados, em linhas gerais, o trabalho de Mauricio García-Durán (2006, p. 21, tradução nossa), intitulado Movimiento por la paz em Colômbia: 1978-2003, apresenta uma análise elucidativa sobre o tema do referido título e tem como argumento inicial a seguinte definição:

Os movimentos sociais [...] são expressões de organização cidadã profundamente legítimas quando articulam as visões e os interesses coletivos de centenas de milhares de pessoas e buscam promover projetos de vida e sociedade renunciando à violência como estratégia para promover a mudança social. Através de processos de organização e ação coletiva mantêm vivos debates aos quais a 
Colômbia não deve renunciar no marco da superação da violência armada e da construção da paz.

$\mathrm{Na}$ complexidade das análises sobre o conflito armado, o narcotráfico, o racismo, a erradicação da pobreza e do analfabetismo - sobretudo no meio rural - e a corrupção política, os teóricos que se dedicam a esses temas candentes destacam a necessidade de maior mobilização social, reconhecendo os inúmeros esforços advindos da organização dos diferentes movimentos sociais (Arboleda, 2002; García-Durán, 2006; Jiménez, 2001; Quiñones, 2010). Ao mergulharmos no universo de questões que envolvem a garantia dos direitos humanos, é possível visualizarmos outros tantos desafios analíticos acerca das idiossincrasias e especificidades testemunhadas por grupos organizados pela defesa de seus direitos. Os autores antes citados enfatizam a centralidade da participação política de organizações que operam regional e nacionalmente e que, nas duas últimas décadas, vêm propondo alternativas de intervenção efetiva perante o Estado.

Sobre esse aspecto, podemos supor que as inúmeras ações dos afro-colombianos implicaram acordos para o fomento de políticas que se constituíram como um marco na história de resistência, sendo esse um traço do avanço da luta antirracista. São estratégias de grande envergadura mobilizando agentes locais representantes de "comunidades palenqueras" (quilombolas) e que refletem um nível de organização com base em uma plataforma de reivindicações que constituem a proposta de Educação Própria. São contribuições apresentadas com base na perspectiva de fomentar uma práxis intercultural, criando um "incômodo curricular positivo", se assim pudermos considerar.

Para compreendermos o papel político desse movimento, pensamos com Arboleda (2011, p. 369) sobre:

[...] las contribuciones a la construcción y consolidación de un pensamiento político, que transforme o refunde el sentido de las ciudadanías y con ello la democracia, estando en el centro la humanización y la igualdad como asunto concreto; así mismo el significado del hombre y lo humano [...] podemos hablar de la búsqueda de ciudadanías transmodernas, "desrracializadas", afianzadas en sus etnicidades.

Notamos, com esse autor, alguns pressupostos da interculturalidade afro-colombiana congregadora e possível para esse estrato que enfrenta inspirações coloniais, como ocorre, também, no Brasil.

A Frente Negra Brasileira (1931-1937) - a mais importante das instituições criadas em São Paulo e extinta por um decreto do presidente Getúlio Vargas ofereceu a uma população marginalizada possibilidades de organização, de crença nos processos educativos e ajuda no combate à discriminação racial. Aos olhos de instituições governamentais e de segmentos negros, sua experiência revela quão determinante foi a opção política construída em conformidade com o ideário do acesso à educação formal e valorização das ancestralidades africanas. 
Agregamos ao conceito de movimento social de García-Durán (2006), aquele que define o movimento social negro (Santos apud Domingues, 2007, p. 102) no Brasil:

Todas as entidades de qualquer natureza, e todas as ações, de qualquer tempo (aí compreendidas mesmo aquelas que visavam à autodefesa física e cultural do negro), fundadas e promovidas por pretos e negros [...] entidades religiosas (como terreiros de candomblé, por exemplo), assistenciais (como clubes de negros), artísticas (como os inúmeros grupos de dança, capoeira, teatro, poesia), culturais (como os diversos centros de pesquisa) e políticas (como o Movimento Negro Unificado) e ações de mobilização política, de protesto antidiscriminatório, de aquilombamento, de rebeldia armada, de movimentos artísticos, literários e folclóricos - toda essa complexa dinâmica, ostensiva ou encoberta, extemporânea ou cotidiana, constitui movimento negro.

Conforme Quiñones (2010), membro da Comissão Pedagógica Nacional na Colômbia, a negação do ser afro-colombiano nos âmbitos sociais, políticos, econômicos e culturais está fortemente marcada nas propostas educacionais apresentadas oficialmente. A realidade vivida por esses agentes políticos obrigou à emergência de movimentos de resistência e reafirmação por parte da referida comunidade. Maguemati Wabgou (2008), pesquisador da área de ciência política no país, considera a influência do movimento social negro ao definir os avanços alcançados nos estudos acadêmicos sobre África. Para além da difusão e a transmissão de saberes, surge a necessidade de contribuir para a construção epistemológica acerca do continente africano na Colômbia com base em uma perspectiva multidisciplinar:

Cabe mencionar que las pocas iniciativas puestas en marcha para insertar el conocimiento sobre África y lo africano en la academia colombiana, se han ido desarrollándose junto con lo afrocolombiano: el estudio de Colombias Negras se desarrollaba con interes particular a los conocimientos africanistas y reforzando la relación antropología-historia africana en sus investigaciones ya que siempre se há buscado formas para reconstruir un puente científico entre la América Latina hispânica y África. (idem, p. 323, grifo do original)

Ao considerarmos tal panorama, podemos supor haver questões nesse debate que sugerem amplas aproximações, para estudos futuros, das especificidades que norteiam as políticas curriculares e as agendas reivindicatórias dos movimentos negros do Brasil e da Colômbia. São temáticas sobre o lugar social das populações afrodescendentes e sua mobilidade socioeconômica e socioeducativa. Por outra parte, a Colômbia enfrenta o fenômeno do desplazamiento forzado, e dados recentes indicam que, no período de janeiro do ano de 2000 até o final do primeiro semestre de 2011, 23,58\% da população deslocada violentamente correspondia a grupos étnicos. E é nesse contexto que a desterritorialização ganha mais peso, por ocorrer justamente quando as comunidades negras estão em pleno processo de titulação coletiva ou acabam de se converter em donos oficiais de seus territórios. 
Por conseguinte, os "direitos étnico-territoriais" dos afro-colombianos estão, cotidianamente, ameaçados (Wouters, 2002).

Como sujeito histórico, o movimento social afro-colombiano experimenta uma agenda extensa de reivindicação de sua pertença, sobretudo quando consideramos este último fenômeno: o deslocamento forçado. Caberia considerarmos o traço intersubjetivo para entendermos os processos que transformam as políticas públicas e educacionais.

Notadamente, a presença africana na região do Pacífico colombiano é uma das partes do mosaico de africanidades dentro de um mesmo país. No bojo das ações governamentais, tornou-se inadiável reconhecer o valor da multidimensionalidade das práticas educativas, por meio da reposição, nos documentos regulatórios, da presença histórica e atual dos segmentos afrodescendentes. Para Quiñones (2010, p. 5), a força dos grupos violentos, que afetou os povos afro-colombianos nessa parte do país - região do Pacífico -, fez com que se buscassem outras formas de resistir, e é por isso que se enfatiza a necessidade de reivindicar e exigir o direito dessa população a uma educação que responda a suas expectativas, necessidades e aspirações como povo culturalmente diferenciado:

A pesar de todos los inconvenientes y prohibiciones que estos grupos imponen a los docentes, líderes y comunidad en general, continúan reflexionando y actuando sobre la posibilidad de un sistema educativo que fomente sus valores culturales que permita reconstruir, reactivar y construir su própia identidad.

São esses alguns dos aspectos que ganham centralidade no exame da dinâmica organizacional de coletivos e sujeitos implicados nas lutas antirracistas na Colômbia.

\section{FÓRUNS INTERCULTURAIS E PRÁXIS POLÍTICA}

Nos fóruns realizados no Brasil para o debate acerca da diversidade e de políticas educacionais, apreendemos aspectos sobre as disputas retóricas na elaboração dos textos orientadores. Nesse cenário foram defendidas propostas que destacaram a urgência de se desenvolverem ações estratégicas no âmbito da política curricular e da formação de professores com o foco na valorização da história dos povos africanos e da Diáspora Africana. Ao considerarmos os contextos de luta pela garantia de políticas antirracistas e as especificidades das dinâmicas adotadas no âmbito dos movimentos afro-brasileiro e afro-colombiano, faz-se necessário investirmos em análises comparativas que levem em consideração as respectivas formas de organização política. Partimos da premissa de que é no bojo da disputa por maior espaço reivindicatório para esses coletivos - aqueles que incluem a questão educacional como eixo norteador - que as noções de diálogos interculturais e de espaços de colaboração encontram sua gênese.

As críticas aos modelos de políticas de inclusão apresentadas nesses fóruns (México, Brasil, Colômbia, Equador), a participação de ativistas visando garantir ações estratégicas para a certificação de etnoeducadores, as táticas de composição de núcleos e de comissões de representantes comunitários, a indicação de 
conselheiros(as) para diferentes órgãos regulatórios, ministérios, bem como os projetos desenvolvidos por instâncias oficiais de governança e, ainda, as formas de pressionar os(as) sucessivos(as) gestores(as) públicos(as), foram ações com forte alcance nessas experiências de confronto com as esferas que representam os governos.

Pensar a(s) cultura(s) considerando o hibridismo como uma marca das sociedades complexas implica a adoção de uma abordagem multidimensional para análises mais fecundas acerca da cartografia existente e que pode ser avaliada quando o interesse é uma maior aproximação com as idiossincrasias da América Latina. Países marcadamente afros e indígenas - mas ao mesmo tempo vitimados pela presença e, posteriormente, pela sombra do colonialismo -, Brasil e Colômbia devem ser considerados como promotores de um discurso de resistência efetiva em termos de formas de denunciar o racismo experimentado e de estratégias dialógicas possíveis para a reversão das narrativas sobre a diáspora negra nas Américas.

Ao levarmos em conta a produção discursiva, podemos considerar que esse debate tem como centralidade os textos com ênfase nos desafios da condição multicultural e as interseções constituídas por tais heranças. As inclinações teóricas e a práxis educadora, orientada a partir do eixo "políticas curriculares para a diversidade", ganham centralidade quando reunimos essas produções para entender os modos de reivindicação de espaços para a inserção de outras narrativas acerca da pertença dos grupos afrodescendentes. Do mesmo modo, nosso vínculo com pesquisadores (Brasil, México, Colômbia e Equador) que trabalham com a temática da educação intercultural e formação de professores(as) orientaram nossos achados teóricos sobre pedagogias alternativas e movimentos sociais.

As insuficiências apresentadas nas experiências de governança - pensada esta com base no ideário da emancipação social, por exemplo - orientaram outros aportes e novas questões de estudo. Foi oportuno, nesse itinerário, levantarmos textos sobre projetos de cooperação com países da região visando realizar mapeamentos que entrecruzaram diferentes dimensões da(s) cultura(s).

Acompanhamos, no México, o Foro de Educación, Ciudadanía e Interculturalidad (Puebla, outubro de 2004), que teve como tema gerador a cidadania com base na perspectiva da transformação das relações entre os membros de diferentes culturas em um mesmo continente. A virada conceitual sobre interculturalidade, entendida por meio das apreensões obtidas nesse espaço de interlocução, está relacionada com os modos de produção de novas epistemologias. À época, vislumbramos outras possibilidades de inserção no campo de debate sobre as propostas educativas com base no ideário da colaboração intercultural.

Posteriormente, o Seminário Internacional Diversidad, Interculturalidad y Construcción de Ciudad (Bogotá, abril de 2007) teve como ponto de pauta a problemática dos grupos organizados na cidade e no campo, no intuito de recompor suas identidades em situações de deslocamento forçado. Uma das preocupações recorrentes foi entender a cidade e a presença do poder público frente aos problemas educacionais a serem administrados no seu cotidiano. O seminário contou com a adesão de um número expressivo de lideranças comunitárias, palenqueras, estudantes, representantes governamentais e acadêmicos de países - tais - como Brasil,México, Equador e Cuba - interessados na defesa de uma educação na e para a diversidade. 
O encontro alcançou resultados consideráveis no que se refere aos modos de serem instituídos novos lugares de diálogo. A presença de representantes ministeriais favoreceu articulações frutíferas e justificadas pela demanda de fóruns permanentes para a promoção de políticas de cooperação no âmbito da América Latina.

O I Seminário Internacional Intercâmbios Afro-Latinos ${ }^{8}$ (Rio de Janeiro; Salvador, julho/agosto de 2007) reforçou o vínculo de cooperação com a Colômbia. No bojo dessas iniciativas, nossas hipóteses avançaram por adotarmos como pressuposto o lugar de importância da Colômbia para a cooperação entre movimentos sociais e afrodescendentes na América Latina. Justificamos, assim, a ênfase na dinâmica organizacional e nas respectivas interpretações acerca da política etnoeducativa.

No VI Foro Latinoamericano de Educación Intercultural, Migración y Vida Escolar (Puebla, novembro de 2009), acompanhamos a reunião de representantes de instâncias governamentais e de movimentos sociais em busca de consolidação de outras ferramentas político-pedagógicas e de novas práxis pedagógicas em espaços escolares e não escolares, bem como sobre a educação na modalidade a distância. As idiossincrasias e especificidades mexicanas incluíram a legitimidade da educação bilíngue, o problema do acesso à escola básica e o compromisso com a democratização da educação para os grupos que ocupam espaços com pouca presença do Estado, notadamente a população indígena camponesa quase que na sua totalidade.

$\mathrm{Na}$ Colômbia, o II Encontro Nacional de História Oral (Bogotá, agosto de 2010) dedicou-se ao tema do desenvolvimento da história de vida como prática metodológica no sentido de ressaltar a relevância dessa perspectiva para a garantia da preservação da memória e do patrimônio de grupos que têm como tradição a oralidade. Os estudos sobre outras metodologias ganharam especial atenção por conta das propostas de valorização de experimentos inovadores com comunidades rurais, entre outros segmentos.

Também em 2010, em Salvador, foi possível compor o Grupo de Trabalho "Cultura e Educação na Integração dos Povos Afrodescendentes" do II Encontro Afro-Latino, II Encontro Ibero-Americano de Ministros da Cultura para uma Agenda Afrodescendente nas Américas e Encontro de Pensadores. O projeto MinC/Fundação Cultural Palmares comemorava, à época, o dia da África, abrigando representantes dos movimentos sociais da América Latina, representantes da Organização das Nações Unidas para a Educação, a Ciência e a Cultura (UNESCO), Fundação Activos Culturales Afro (ACUA), além de cerca de 120 intelectuais do Equador, Colômbia, Cuba e Venezuela, bem como representantes de países africanos parceiros. Um dos resultados comemorados no evento foi a criação do "Observatório Afro-Latino e Caribenho", abrigado pelo Centro Nacional de Formação e Referência da Cultura Negra (MinC/Fundação Cultural Palmares). O portal foi proposto no I Encontro Ibero-Americano: Agenda Afrodescendente nas Américas (outubro de 2008), sendo esta a primeira reunião regional realizada por

8 Seminário idealizado pela Fundação Cultural Palmares, em 2010, e que ocorreu em duas etapas, incluindo Rio de Janeiro e Salvador, com adesão expressiva de estudantes e coletivos de movimentos sociais das duas cidades, bem como acadêmicos de fora do Brasil. 
governos da América Latina e Caribe visando fomentar a cooperação nos processos de valorização da cultura negra. Consequentemente, a Declaração de Cartagena tornou-se um marco do movimento de aliança entre os países mencionados.

O II Encontro Afro-Latino contou com a presença do então ministro brasileiro da Cultura, Juca Ferreira (entrevista coletiva de imprensa), que justificou o encontro como forma de:

[...] construir cooperação, troca de experiência, construção de políticas públicas voltadas para a construção de igualdade racial no nosso continente, a América Latina, no Caribe, essa articulação já envolve praticamente todos os países. [...] Nós estamos desenvolvendo um conceito de patrimônio que vá além da casa grande. Nós temos reconhecido a importância da cultura negra no Brasil, das suas manifestações culturais tradicionais.

A declaração da ministra da Cultura do Equador, Erika Charvet (25 de maio de 2010, Salvador), foi enfática: “[...] las élites no tenían una identificación con la cultura nacional popular de los grupos afrodescendientes, de los grupos indígenas, de los grupos mestizos. Justamente el gobierno de Rafael Correa pone a la Cultura en el centro de la preocupación del Estado". Nos termos de Fairclough (2008, 2010), entendemos os fragmentos das declarações acima como parte de visões transitórias em discursos oficiais. Contudo, o evento exigia tais produções por estar incluído em uma prática social de mudança. A proposta vislumbrava a conformação de uma agenda comum, com foco na cooperação para estabelecer ambiências dialógicas.

A condição de "ministros" apresenta implicações significativas no modo de revelar as posições políticas desejáveis. São atores políticos e a performance se dá em função daquilo que se espera ouvir desses representantes. Toda prática inclui sujeitos, atividades, objetos, instrumentos, tempo e lugar (Fairclough, 2010, p. 225). A consciência e o discurso promovem a compreensão de elementos dialeticamente relacionados nas formas de expressão dos fragmentos dos discursos do ministro do Brasil e da ministra da Colômbia. Representar governos implica a adoção de um dado discurso que pode ser incorporado ou não pelo coletivo interessado. Seus discursos são representações da vida social, derivadas das posições assumidas. Reconhecer o problema da subjugação e hierarquização racial que afeta os não brancos no âmbito da América Latina pode ser uma prática discursiva orientadora de coletivos como organizações afro-colombianas e afro-brasileiras.

No ano de 2011, em Bogotá, o I Encuentro Internacional de Educación y Pedagogía focava o debate em outras experiências e práticas para além da escola, bem como em novas tendências e diálogos sobre educação. Acompanhamos, na ocasião, propostas de estudos com ênfase nas práticas pedagógicas voltadas a comunidades camponesas, cujas realidades urbanas e rurais são desafiadoras na medida em que os obstáculos impostos pela pobreza na interseção com a diversidade figuram como um grande nó para gestores públicos e grupos comunitários organizados. No mesmo período, foi possível participar simultaneamente do fórum Reparaciones a Víctimas de Pueblos Afrocolombianos, Negros, Raizales y Palenqueros e do Encuentro de Culturas Afrodescendientes, Festival Sul-Sur y Festival Antero Agualimpia (novembro de 2011). 
Podemos considerar alguns registros de cunho etnográfico ao longo desse processo de analisar/interpretar o debate em curso no âmbito dos movimentos sociais negros latino-americanos. Etnografar bem como analisar criticamente fragmentos de declarações, discursos oficiais de alguns representantes de instâncias públicas, documentos regulatórios, propostas pedagógicas alternativas e textos introdutórios de materiais didáticos, resultou na construção de um mosaico discursivo sobre educação e interculturalidade. São nuances reveladoras para quem deseja compreender as disputas retóricas sobre o que se produziu nas últimas décadas no enfrentamento de segmentos opostos em realidades multiculturais.

Os traços de confronto são categorias analíticas para uma interpretação crítica de discurso no sentido dado por Norman Fairclough $(2008,2010)$. Apreendemos concepções e especificidades de uma perspectiva intercultural latino-americana para a educação e aproximamo-nos de teorias sobre a dinâmica dos movimentos sociais. No I Seminário Internacional Pensamiento Afrodiaspórico en la América Andina Programa de Pós-Graduação em Estudos da Cultura da Universidade Andina Simón Bolívar (Quito, abril de 2012) -, percebemos a defesa pela legitimação de uma educação intercultural a partir dos saberes tradicionais, entre outros aportes.

\section{DIÁLOGOS INTERCULTURAIS NA PERSPECTIVA AFRO-COLOMBIANA: POR UMA EDUCAÇÃO PRÓPRIA}

Segundo a crítica pós-colonial (Said, 1995, 2003; Fanon, 2008), a normalidade é a brancura da cor da pele, fato esse justificável quando consideramos a aventura europeia como o fato social gerador dessa supremacia. A brancura é uma marca da normalidade e pode ser invisibilizada como tal na medida em que não é percebida como parte da identidade branca. A gênese da "normalidade do ser branco" $\mathrm{e}$, consequentemente, da supremacia da brancura - um traço identitário definido por esse fenômeno-, passa a ser um aspecto fundamental no quadro teórico sobre a denúncia de conservação de referenciais eurocentrados na seleção do conhecimento legitimado em uma dada sociedade.

Santiago Castro-Gómez (2010) adverte que na América Latina não há como falarmos de modernidade e colonialidade como fenômenos sucessivos, mas sim como simultâneos no espaço. Analisando a consolidação do projeto imperial e civilizatório que atingiu a região, salienta que a modernidade é um fenômeno do sistema-mundo que emerge como um saldo de modelos de administração adotados por diferentes impérios europeus. Esses modelos deixam de ser fenômenos europeus passando a ser mundiais, caracterizados por relações assimétricas entre o continente europeu e o chamado "resto do mundo". Na experiência de subjugação, Colômbia herda uma racionalidade baseada no "dispositivo de blancura":

El dispositivo de blancura consiguió articularse con el dispositivo biopolítico pero colocándolo siempre bajo su hegemonia. Lo que prevaleció en la Nueva Granada fue aún después de las guerras de la independencia, fue la lucha entre una multiplicidad de intereses regionales y patrimoniales que buscaban hacerce del control 
del Estado. Pero también prevaleció durante mucho tiempo la racionalidad básica del dispositivo de blancura: el ordenamiento social de la población conforme uma jerarquia fundada en la limpieza de sangre. (idem, p. 348)

Um desafio que se coloca é o de apreendermos a imbricação do conceito de interculturalidade na visão dos movimentos sociais negros. As questões geopolíticas impostas pela condição de dominação na América Latina, por um lado e por outro, e a resistência dos grupos afrodescendentes e indígenas, conforme destaca Catherine Walsh (2009), fazem-nos supor que a interculturalidade pode ter mais de um significado e, nesse caso, forma parte de um pensamento outro construído por um lugar político particular de enunciação de grupos insurgentes, como pudemos apontar nas análises textuais, discursivas.

Durante a primeira década do século XXI, buscamos conhecer e vivenciar concepções sobre diálogos colaborativos no intuito de participar desse fórum inesgotável, tendo como pano de fundo o objetivo de apreender nuances dos discursos produzidos no interior dos movimentos e dos congressos sobre interculturalidade, etnoeducação afro-colombiana e Educação Própria.

Em seu trabalho Educación pertinente, Harah Olof Ylele (2010) defende uma retomada do sistema educacional via proposta da etnoeducação afro-colombiana. Sobre o marco geral do modelo do Buen Vivir Minga, afirma que "la organización de nuestro pueblo es pilar fundamental para su dignificación y liberación" (idem, p. 15):

La Etnoeducación o cualquiera sea el nombre que finalmente adoptemos para el modelo educativo, no es un fenômeno aislado, es una estratégia que forma parte de la cosmovisión del pueblo Afro en Colombia, con miras a construir un nuevo ser para una nueva sociedad en donde primen los valores supremos de la humanidad. Entiéndase como humanidad, el rescate de sus valores intrínsecos, sobre todo del respeto y de la solidariedad contenidos en ella. (idem, ibidem)

Nossa inserção nos espaços de debates, junto ao movimento afro-colombiano, revelou idiossincrasias de sua dinâmica, conforme indica o fragmento anterior. Apreendemos distintas concepções sobre as formas de se proporem espaços dialógicos entre os sujeitos implicados. Tal como acontece no Brasil, optou-se pelo diálogo com o Estado, reinterpretando a perspectiva intercultural presente no discurso oficial (estabelecido) com o propósito de aproximar esse mosaico de proposições e sugerir caminhos de reinvenção conceitual acerca das abordagens pedagógicas

9 O modelo Buen Vivir Minga de los Afrocolombianos é composto por cinco eixos centrais de trabalho (organização, território, etnoeducação, desenvolvimento e participação) que orientam a dinâmica das suas organizações. É definido por Harah Olof Ylele (2010, p. 19-20) como uma proposta em construção para garantir transparência na organização da vida coletiva, controle do território, evitando apropriação individual, o resgate do papel da educação e um modelo de desenvolvimento próprio. Inclui maior aproveitamento dos recursos, bem como uma participação diversificada e integradora. Busca-se uma conexão com os propósitos das diferenças étnicas e culturais. 
construídas no âmbito das comunidades. No argumento de Jorge Henrique García Rincón (2008), os afro-colombianos não podem abrir mão do "direito ancestral" ou "direito próprio", por meio do qual se reconhece uma cultura particular. Assim,

A afro-colombianidade em suas diversas expressões não é apenas uma categoria cultural, mas também uma categoria política que se expressa de forma concreta nas dinâmicas organizativas que constituem o movimento social. Desse modo, gera-se um cenário de debate e diálogo entre a comunidade afro e o Estado colombiano que no campo da educação se concretizou na criação da Comissão Pedagógica Nacional de Comunidades Negras. (idem, p. 5, tradução nossa)

Nessa conformação política e dialógica, os discursos analisados indicam que o movimento social tem como pressuposto garantir alguma autonomia para autogovernança educativa - uma forma de tradução do ideário da Educação Própria. Lideranças, etnoeducadores, pesquisadores, diferentes grupos e "comunidades palenqueras" (quilombolas) estão comprometidos com uma agenda na qual a Educação Própria passou a ser uma linguagem, uma proposta pedagógica intercultural afro-colombiana. Portanto, a afro-colombianidade passa a ser compreendida como parte de uma tradução do ideário da negritude, que atravessa séculos como consciência coletiva de uma diáspora fincada em terras latino-americanas em grande escala.

Por ocasião do I Fórum Nacional de Etnoeducação Afrocolombiana (2002, p. 138), as organizações de comunidades declararam:

Que se hace necesario articular discurso y práctica para dar aplicación a la política de etnoeducación afrocolombiana y cumplimiento a la normatividad establecida. Que es necesario que las instituciones formadoras de docentes reformulen sus currículos, teniendo en cuenta los lineamientos de la política etnoeducativa afrocolombiana y la Cátedra de Estudios Afrocolombianos, en procura de reconocer, de manera efectiva en la sociedad colombiana, los aportes de esta cultura al país y a la humanidad, promocionar su conocimiento e informar a la actual y nuevas generaciones.

O fragmento citado nos remete ao pressuposto contido no livro Sube la marea: Educación Propia y autonomia en los territórios negros del Pacífico (2008), de Jorge Henrique García Rincón (2008, p. 25), sobre os desafios a serem enfrentados pelo sistema educativo colombiano:

No hay duda que uno de los grandes retos que tiene el sistema de ensino colombiano es el acompañamiento al diseño de modelos educativos y pedagógicos en la diversidad. Solo que estos modelos no deben reducirse a la promulgación de normas y la formulación de lineamientos curriculares que nadie asume de manera real. La propuesta debe ser de tal calibre que penetre la consciencia nacional a través del desarrollo de una estratégia agresiva de educación por los medios masivos. 
Podemos supor que a ideia de integração adotada no discurso oficial do Estado colombiano está marcada por disjunções quando consideramos o trecho antes citado. Percebe-se tentativas de recomposição das distintas subjetividades por via de garantias legais. Decerto o manifesto do I Fórum Nacional de Etnoeducação Afrocolombiana é uma reação que guarda uma dimensão político-pedagógica nos seus princípios. Ao que tudo indica, a resistência das comunidades provocou a promulgação do decreto n. 1.122 - ou Cátedra de Estudios Afrocolombianos -, que tornou obrigatória a inclusão dos conteúdos para todo o sistema educativo nacional. De qualquer modo, e contando com a fundamentação legal, muitas maneiras de racismo mudaram a maquiagem e, apesar das lutas e da presença da ONU, existem setores em que tais manifestações se fazem evidentes.

O debate que fomentou o fórum Reparaciones a Víctimas de Pueblos Afrocolombianos, Negros, Raizales y Palenqueros (Bogotá, 2011), organizado pela Comisión Nacional de Reparación y Reconciliación, ofereceu-nos pistas para as análises de conversações e para a adoção de uma abordagem metodológica intersecional. Acompanhamos diferentes segmentos ao questionarem a falta de resposta do Estado e de órgãos parceiros - internacionais e nacionais - no que tange ao problema da violência e da falta de propostas de restituição de terras e inclusão da perspectiva afrodescendente de educação.

No dizer de Santiago Arboleda (2002, p. 400), os afro-colombianos demarcaram esferas de reconstrução e organização social de impacto, com destaque para as manifestações religiosas e atividades artísticas diversas que evidenciam estratégias organizativas invalidadas por diferentes discursos sobre o desenvolvimento. Assim, o discurso por uma Educação Própria é a perspectiva afrodescendente para a formação e recolocação do sujeito afro-colombiano. Essa abordagem parece fomentar outras propostas que garantam o debate sobre a adoção de práticas diferenciadas por ser a diversidade cultural o desafio mais caro para o Estado colombiano.

Considerando a multiculturalidade como um dos mais importantes traços da sociedade colombiana, podemos supor que os afro-colombianos convocam a conformação de espaços dialógicos para o debate mais amplo sobre alteridade, para supostas mudanças de status de um segmento antes invisível. Não obstante, a efetivação de mudanças profundas em termos da garantia da cidadania afro-colombiana parece depender de um volume maior de denúncia e mobilização.

Analisamos a Educação Própria como uma proposta político-pedagógica legítima que nasce da reapropriação da diversidade cultural e do reconhecimento da presença afrodescendente. Constitui-se como um atalho para o protagonismo de outros agentes políticos com base na perspectiva do "direito étnico-ancestral" ou "direito próprio", conforme acentuou Jorge Henrique García Rincón (2008). No bojo desse ideário, o movimento social afro-colombiano é um agente comprometido com as políticas para a diminuição das desvantagens sociopolíticas e educativas, orientado pela conformação de espaços de diálogo e mudanças para um maior reconhecimento da pertença social de sujeitos da diáspora africana. São posicionamentos que, ao que tudo indica, refletem os processos políticos de mobilização e embates fomentados pelas instituições diversas e de grupos de intelectuais parceiros situados nos espaços acadêmicos. 
Podemos supor que essa perspectiva discursiva impulsiona o autoconhecimento por incluir uma práxis intercultural de educação que afeta positivamente o conjunto da sociedade. "O direito étnico-ancestral" ou "direito próprio" (García Rincón, 2008) emerge como balizador desse processo. Potencializa e valoriza as relações humanas ao mesmo tempo em que esbarra no desafio imposto pelo dispositivo da brancura (Castro-Gómez, 2010). Decerto, a conformação das agendas que fomentam os movimentos sociais na América Latina nos impõe perspectivas outras para o estabelecimento de diálogos interculturais para uma maior aderência das propostas de respeito aos direitos desses segmentos. Isso porque "las histórias (trans)locales y las acciones de estos movimientos confrontan los legados y las relaciones del colonialismo interno" (Walsh, 2007, p. 48-49).

Vimos como países como o Brasil e a Colômbia apresentam aspectos relevantes para os estudos sobre a agência política de movimentos sociais latino-americanos por imporem uma pauta reivindicatória em consonância com as disputas por espaços de representação, reconfigurando setores importantes da sociedade. Por conseguinte, tornou-se um imperativo criar mecanismos de cooperação e debate no âmbito dos movimentos comprometidos com o fomento de lugares epistêmicos de orientação mais plural e menos monolítica.

Caberia situarmos a agenda afro-colombiana como parte daquilo que Catherine Walsh (2008, p. 45) define: uma proposta de pedagogia decolonial; uma possibilidade de pôr em cena o racismo, a desigualdade e a injustiça, de vislumbrar caminhos e práticas voltadas à transformação. Pensamos com a autora uma interculturalidade concebida como projeto social, político, ético e epistemológico. A decolonialidade, por sua vez, é no bojo a estratégia, a ação e o requisito (idem, ibidem). $\mathrm{Na}$ composição de um quadro teórico sobre outros lugares discursivos advindos dos movimentos sociais, seriam esses os incrementos necessários para o relevo das disputas político-pedagógicas aqui em destaque. Processos decoloniais podem ser oportunidades de estabelecermos diálogos mais inter, menos hierárquicos nos projetos educativos, nas formas de pensarmos as políticas públicas e no modo de representarmos os outsiders negros, nos termos de Edward Said (1995).

A luta dos afro-colombianos pode ser avaliada como resultado da conscientização política, que revela o quanto o poder sobrevive, toma novas formas e assume estratégias outras de subalternização, inclusive em sociedades multiétnicas e culturalmente diversas (Walsh, 2008). O debate mais amplo que aparece neste artigo, como escopo para pensarmos a agência política de sujeitos históricos subjugados com a sua invisibilização, permite-nos recolocar essas narrativas, e, por esse prisma, tornam-se imprescindíveis estudos que possam balizar outros casos particulares existentes nos diferentes países submetidos ao poder colonial e marcados pelo dispositivo da brancura no sentido de Castro-Gómez (2010).

Para este estudo, chamaram atenção os processos iniciados no Brasil e na Colômbia. Seguimos os passos de Walsh (2008) quando concebe a interculturalidade como prática anti-hegemônica, buscando reverter a designação de alguns conhecimentos como legítimos e universais e a relação de outros, especialmente aqueles relacionados à natureza, ao território, à ancestralidade e ao espaço local de saberes. 
Podemos supor que a perspectiva intercultural de educação dos afro-colombianos seja uma possibilidade de ampliação de propostas oriundas dos movimentos antirracistas em toda a América Latina.

\section{PARA CONCLUIR}

Contextos marcadamente desiguais separam e hierarquizam grupos humanos colocando-os em lados opostos: não racializados (estabelecidos) e racializados (outsiders) e podem gerar, ao mesmo tempo, as redes de cooperação entre segmentos afins nesse ambiente. Com base na experiência colombiana compartilhada em distintas etapas e nos estudos sobre a agência política dos afrodescendentes na América Latina, nossa análise apresentou, como pano de fundo, a agência do movimento social afro-colombiano na luta político-pedagógica, conforme a análise discursiva da proposta de uma Educação Própria em andamento também no Brasil. Este estudo pode contribuir para uma reflexão mais ampla sobre as heranças coloniais na região e as inspirações que esse fenômeno provocou, fixando lugares opostos que inferiorizam grupos pela sua racialização. Encontramos não só pistas sobre as formas de garantir a participação política, mas também oportunidades de novos lugares enunciativos, aquilo que chamamos de lugares epistêmicos outros com ênfase nos pressupostos advindos das disputas retóricas presentes nos congressos e seminários que aqui ganharam destaque.

Acompanhamos os fóruns mergulhados no ideário intercultural e etnoeducativo. Questões sobre a Educação Própria e o direito à preservação da Memória Afrodescendente na Colômbia e de preservação dos territórios ancestrais emergiram com maior densidade. As formas de resistência e as chances de mudanças no que concerne aos efeitos do dispositivo da brancura (Castro-Gómez, 2010), ainda em erupção, dependerão de novas estratégias também legais para inibir a desumanização e a invisibilização dos não europeus da América Latina. Sua agenda político-pedagógica faz emergirem novos modos de concebermos o conhecimento de referência e os sujeitos sociais implicados nos processos educativos que ocorrem em espaços formais e não formais de educação.

Insistimos na defesa de uma abordagem que sugira projetos decoloniais de sociedade, iniciativas que possam recolocar os grupos não brancos - em diferentes partes do mundo - não mais como outsiders, mas como sujeitos de suas narrativas. Isso porque incluir suas narrativas, reescrever sua própria história e a história de África pelo mundo - na diáspora -, significa, então, preservar africanidades potencializando, com isso, a pluralidade das experiências dos segmentos afrodescendentes em todo o globo.

\section{REFERÊNCIAS}

Arboleda, Santiago. Paisajes, colonias y mobilización social afrocolombiana en el suroccidente colombiano. In: Mosquera, Claudia; Pardo, Mauricio; Hoffmann, Odile (Orgs.).Afrodescendientes de las Américas: trayectorias sociales e identitárias: 150 años de 
abolición de la esclavitud en Colombia. Bogotá: Universidad Nacional de Colombia; ICANH, IRD, ILSA, 2002. p. 399-419.

. Le han florecido nuevas estrellas al cielo: suficiencias íntimas y clandestinización del pensamiento afrocolombiano. 2011. Tese (Doutorado) - Universidad Andina Simón Bolivar, Quito, 2011.

CAndau, Vera Maria. Educação intercultural no contexto brasileiro: questões e desafios. Disponível em: <http://www.maxwell.vrac.puc-rio.br/7460/7460.HTM>. Acesso em: 3 jan. 2013.

Direitos humanos, educação e interculturalidade: as tensões entre igualdade e diferença. In:__. Educação intercultural na América Latina: entre concepções, tensões e propostas. Rio de Janeiro: 7Letras, 2009. p. 154-173.

Cantor, Roberto Burgos. Ruta de libertad: 500 anos de travesía. Bogotá: Ministério da Cultura, 2010.

Castro-Gómez, Santiago. Tejidos oníricos: movilidad, capitalismo y biopolítica em Bogotá (1910-1930). Bogotá: Editorial Pontifícia Universidad Javeriana, 2009.

- La hybris del punto cero: ciência, raza e ilustración en la Nueva Granada. Bogotá: Editorial Pontifícia Universidad Javeriana; Instituto de estudios sociales y culturales Pensar, 2010.

Charvet,Erika. Conferência.In:Encontro Afrolatino-Encontro Iberoamericano de Ministros da Cultura, Agenda Afrodescendente das Américas, 2., 2010. Salvador: Fundação Palmares; Ministério da Cultura, 2010. (Comunicação oral, 1 CD-Rom).

Chevallard, Yves. La transposición didáctica: del saber sabio al saber enseñado. Buenos Aires: Aique, 1991.

Colômbia. Ministério de Cultura da Colômbia. Biblioteca de literatura afrocolombiana. Bogotá: 2010. (Texto de quarta capa)

. Ministério de Educación Nacional. Cátedra de estudios afrocolombianos. Bogotá: Maya, 2001. (série Lineamientos Curriculares)

Decreto n. 1.122, de 18 de junho de 1998. Disponível em: <http://www. mineducacion.gov.co/1621/articles-86201_archivo_pdf.pdf>. Acesso em: 10 set. 2014.

Congresso de La Republica de Colombia. Ley General de Educación, lei n. 115, de 8 de fevereiro de 1994. Disponível em: <http://www.oei.es/quipu/colombia/ Ley_115_1994.pdf>.Acesso em: 10 set. 2014.

Ley 70, de 27 de agosto de 1993. Ley de las Comunidades Negras. América Negra, n. 6. 1993. Diario Oficial, n. 41.013, 31 ago. 1993. Disponível em: <http://www. acnur.org/biblioteca/pdf/4404.pdf?view=1 >. Acesso em: 10 set. 2014.

Domingues, Petrônio. Movimento Negro Brasileiro: alguns apontamentos históricos. Tempo, Rio de Janeiro: Departamento de História da UFF, n. 23, p. 100-122, 2007.

Elias, Norbert; Scotson, John L. Os estabelecidos e os outsiders. Rio de Janeiro: Jorge Zahar Editora, 2000.

FAIrclough, Norman. El análisis crítico del discurso como método para la investigación en ciencias sociales. In: WodAK, Ruth; Meyer, Michael (Orgs.). Métodos de análisis crítico del discurso. Barcelona: Gedisa, 2003. p. 179-203. 
. Discurso e mudança social. Brasília: Editora Universidade de Brasília, 2008.

. A dialética do discurso. Revista Teias, Rio de Janeiro: ProPED/UERJ, v. 11, n. 22, p. 225-234, maio/ago. 2010.

FAnon, Frantz. Pele negra, máscaras brancas. Salvador: EDUFBA, 2008.

García-Durán, Mauricio. Movimiento por la paz en Colombia: 1978-2003. Bogotá: Publicaciones CINEP, 2006.

García Rincón, Jorge Henrique. Sube la marea: Educación Propia e autonomía en los territórios negros del Pacífico. Tumaco: Edición propia, 2008.

Goffman, Erving. Estigma: notas sobre a manipulação da identidade deteriorada. 4. ed. Rio de Janeiro: LTC, 1988.

JimÉnEz, Leonardo Reales. Situación de los afrodescendientes de Colômbia y el cumplimiento de los objetivos de desarrollo del milenio. Informe alternativo de Colômbia, 2005. Mimeografado.

Lopes, Alice Ribeiro Casimiro. Conhecimento escolar: ciência e cotidiano. Eduerj: Rio de Janeiro, 1999.

Ministério de Educación Nacional da Colombia. Memorias del I Foro Nacional de Etnoeducación Afrocolombiana (Declaración de las Organizaciones de Comunidades Negras). Bogotá, 2002.p. 138.

QuiÑones, Fanny Milena. Una mirada de la educación: etnoeducación y conflicto en los territórios afrocolombianos. Educación y Cultura, Bogotá: CEID, n. 86, p. 60-67, mar. 2010. SAID, Edward Waide. Orientalismo: o Oriente como invenção do Ocidente. São Paulo: Companhia das Letras, 1990.

Cultura e imperialismo. São Paulo: Companhia das Letras, 1995.

Cultura e política. São Paulo: Boitempo, 2003.

WABGou, Maguemati. Estudios africanos en Colombia desde ciências políticas y sociales. In: LeChini, Gladys. Los estudios afrocolombianos y africanos en América Latina: herencia presencia y visiones del outro. Argentina: Consejo Latino-Americano de Ciencias Sociales, 2008. p. 321-339.

Walsh, Catherine. Estudios culturales latino-americanos. Retos desde y sobre la Región Andina. Quito: Universidad Simón Bolívar; Ediciones Abya-Yala, 2003.

. Interculturalidad y colonialidad del poder: un pensamiento y posicionamiento "otro" desde la diferencia colonial. In: Castro-Gómez, Santiago; Grosfogel, Ramón. El giro decolonial: reflexiones para una diversidad epistêmica más alá del capitalismo global. Bogotá: Siglo del Hombre Editores; Universidad Central, Instituto de Estudios Sociales Contemporáneos; Pontifícia Universidad Javeriana, Instituto Pensar, 2007. p. 47-62.

Interculturalidad crítica. Pedagogia decolonial. In: Amaya A., Wilmer Villa; Bonilla Grueso, Arturo (Orgs.). Diversidad, interculturalidad y construcción de ciudad. Bogotá: Universidad Pedagógica Nacional, 2008. p. 44-63.

Wouters, Mieke. Comunidades negras, derechos étnicos y desplazamiento forzado en el Atrato medio: respuestas organizativas em medio de la guerra. In: Mosquera, Claudia; Pardo, Mauricio; Hoffmann, Odile (Orgs.). Afrodescendientes de las Américas: trayectorias sociales e identitarias: 150 años de abolición de la esclavitud en Colombia. Bogotá: Universidad Nacional de Colombia; ICANH, IRD, ILSA, 2002. p. 369-397. 
YLELE, Harah Olof. Educación pertinente: guía conceptual y práctica para su construcción e implementación. Bojayá: Organización Étnica de Comunidades Afros Los Palenkes, 2010. (Coleción Enfoque Afro)

\section{SOBRE A AUTORA}

Claudia Miranda é doutora em educação pela Universidade do Estado do Rio de Janeiro (UERJ). Professora da Universidade Federal do Estado do Rio de Janeiro (UNIRIO).

E-mail: miranda1112@globo.com

Recebido em março de 2013 Aprovado em novembro de 2013 